\title{
SER MULHER E MIGRANTE: DEBATES SOBRE DIVISÃO SEXUAL DO TRABALHO NOS FLUXOS MIGRATÓRIOS
}

\author{
BEING A WOMAN AND MIGRANT: DEBATES ON SEXUAL \\ DIVISION OF LABOR IN MIGRATORY FLOWS
}

Ivna de Oliveira Nunes ${ }^{1}$

\begin{abstract}
RESUMO: O presente artigo busca analisar, a partir das discussões sobre divisão sexual do trabalho, a participação das mulheres migrantes no mercado de trabalho. O arcabouço teórico-analítico foi construído a partir de uma revisão bibliográfica que permeia os debates de gênero e mobilidade humana. Considera-se que no contexto atual a intensificação das migrações internacionais, ocasionada pelos efeitos da mundialização do capital, vem carregada do aumento da exploração da mão de obra migrante, sobretudo das mulheres racializadas. Estas estão concentradas nos trabalhos mais precários e informais, permeados por violação de direitos, racismo e discriminação e estão, consequentemente, mais empobrecidas. Este cenário é justificado pela divisão sexual do trabalho como forma de acumulação capitalista.
\end{abstract}

PALAVRAS-CHAVES: Migração; Trabalho; Divisão Sexual do Trabalho.

ABSTRACT: This article seeks to analyze, based on discussions on the sexual division of labor, the participation of migrant women in the labor market. The theoretical-analytical framework was built from a bibliographic review that permeates the debates on gender and human mobility. It is considered that, in the current context, the intensification of international migrations, caused by the effects of the globalization of capital, comes loaded with the increased exploitation of migrant labor, especially of racialized women. These are concentrated in the most precarious and informal jobs, permeated by violation of rights, racism and discrimination and are, consequently, more impoverished. This scenario is justified by the sexual division of labor as a form of capitalist accumulation.

KEYWORDS: Migration; Labor; Sexual and Racial Division of Labor

\footnotetext{
* O presente artigo é fruto de reflexões desenvolvidas na minha tese de doutorado em andamento que tem como tema "Trabalho e migração de mulheres haitianas em Mato Grosso" a ser apresentada em julho de 2021 pelo programa de Políticas Sociais da Universidade de Brasília - UnB

${ }^{1}$ Docente do Curso de Serviço Social na Universidade Federal de Mato Grosso. Doutoranda do programa de Pós Graduação em Políticas Sociais - Universidade de Brasília - UnB. Email: ivnanunes@gmail.com
} 
Migração contemporânea e o lugar das mulheres nos fluxos migratórios.

O presente trabalho busca analisar a participação das mulheres no mercado de trabalho. A compreensão da inserção e permanência destas em atividades laborais perpassa pelo entendimento de duas mediações: a de "ser migrante" e ser mulher. Estes dois aspectos não podem ser compreendidos como momentos separados, mas articulados dentro de uma totalidade que quando imbricados e associados a divisão sexual do trabalho, endossam que os afazeres destas estão, majoritariamente, vinculados à esfera de reprodução social e que são, portanto, invisíveis e realizados na sobrecarga de trabalhos.

Esta reflexão é parte de uma análise inicial que compõe a tese de doutoramento que aprofunda as discussões sobre mobilidade humana e divisão sexual e racial de migrantes que se deslocam do Sul Global para o Brasil. Para este texto aprofundamos as causas estruturais que impulsionam as mulheres a se deslocarem e buscamos compreender como estas estão inseridas no mercado de trabalho. Partimos assim, de uma análise metodológica qualitativa por meio de referenciais teóricos e de dados pautados em leituras e documentos sobre a divisão sexual do trabalho e a mobilidade humana.

O fenômeno da mobilidade humana contemporânea tem reconfigurado os espaços geográficos, as economias, os estados nacionais, mas também a forma como os sujeitos estão imbricados nos deslocamentos. A concepção da mobilidade humana utilizada neste texto, que tem como expressão a migração, é constituída por aspectos sociais e econômicos que relacionam a mobilidade física, a mobilidade centrada no trabalho e a mobilidade social inseridas em uma totalidade de determinações que não desmembram apenas em aspectos individuais ou na busca por desenvolvimento, mas no modo o qual o sistema capitalista tem se apropriado das migrações para expropriar a força de trabalho. Esses elementos articulados as estratégias de acumulação do capital, pós crise de 1970, de reorganização do capital por meio da acumulação flexível, da reestruturação produtiva e do fortalecimento do Estado neoliberal, constituem o cenário da migração atual. (SANTOS, 2014) 
A organização da sociedade pós 1970 traz como elemento principal conglomerados de poder político, econômico e cultural sem centralidade territorial, mas presente em todos os países. A denominada desterritorialização açambarca não somente blocos ou empresas, mas também indivíduos que se deslocam pelos espaços. Neste sentido, observamos que a mobilidade social dentro do território global realiza-se em um permanente movimento de contradição entre a liberdade absoluta para o mercado capitalista transnacional e o impedimento de ir e vir das pessoas em busca de trabalho e oportunidades.

Cabe ressaltar que a lógica de acumulação do capitalismo mundializado dos últimos anos tem gerado não só uma maior concentração de renda, mas uma "nova lógica de expulsões". Conforme Sassen (2016), pessoas, empresas e lugares estão sendo expelidos do centro da ordem econômica e social, sobretudo um contingente da população pobre de suas terras, empregos e moradias. As expulsões, segundo a autora, dadas a partir de 1980, acontecem com a mudança de áreas econômicas essenciais e que se desmembram em áreas de baixo custo e pouca regulamentação, e, de outro, cidades globais onde estão as redes centrais de poder. Portanto, o aumento do número de pessoas deslocadas está relacionado à intensificação das desigualdades, a terceirização e informalidade, desemprego, pobreza e encarceramento:

Além disso, existem inúmeras pessoas deslocadas, armazenadas em campos formais e informais de refugiados, os grupos convertidos em minorias nos países ricos e que são amontoados em prisões e os homens e mulheres em boas condições físicas que estão desempregados e armazenados em guetos e favelas. [...] Em suma, o caráter, o conteúdo e o local dessas expulsões variam enormemente, atravessando estratos sociais e condições físicas no mundo inteiro (SASSEN, 2016: 11).

Nos últimos anos, a massa da população disponível para o mercado de trabalho intensificou-se devido a expropriação materializada pela mundialização do capital que altera as condições de vida e de trabalho, na medida em que seus impactos se verificam não apenas na economia, mas influenciam também a organização socioeconômica, política e cultural da 
sociedade. $\mathrm{O}$ modo de produzir, distribuir e acumular bens materiais atrelados à relação de produção e reprodução do capital também são transformados, acentuando a concentração de renda e a pobreza. Este cenário ocasiona um aumento no fluxo migratório (forçados ou não) modificando as relações com as cidades e meio ambiente e as relações sociais, encontrando barreiras linguísticas, culturais, geográficas, étnicas, religiosas, sexuais, dentre outras.

Neste sentido, a utilização da força da mão de obra de migrantes é um dos principais aspectos da desvalorização da força de trabalho, pois representa a força de trabalho reserva que movimenta a lógica de extração do mais valor do capital por meio da diminuição dos custos do trabalho, pela flexibilidade, irregularidade que impulsionam situações de subordinação e vulnerabilidade. Assim, a força de trabalho de migrantes é funcional ao capital e existe num paralelo entre a necessidade de manutenção da população migrante, ao tempo da sua descartabilidade em épocas de crise.

No momento atual, marcados por ausência de um Estado que garanta a efetivação das políticas públicas e dos direitos a classe trabalhadora, o Estado neoliberal tem efetivado cortes orçamentários para serviços básicos (saúde, educação, assistência social, etc) e gerado um recrudescimento dos direitos sociais e das lutas, acirrando a necessidade de deslocamento entre os lugares na busca de sobrevivência, inclusive entre os países de capitalismo dependente. Assim, compreender o trabalho de imigrantes, neste cenário, requer o entendimento que são, em sua maioria, os deslocados dos países periféricos, os mais atingidos, em específico, a mão de obra feminina e racializada (VILLEN, 2015).

Dados publicados pela Organização Internacional do Trabalho no relatório “Tendências do Emprego Global 2019", revelam que mais de 172 milhões de pessoas não estavam empregadas e mais de 700 milhões de pessoas viviam na extrema ou moderada pobreza, mesmo empregadas, visto que as condições de trabalho não melhoraram. Dos números de pessoas que estão 
trabalhando, a desigualdade de gênero permanece com $48 \%$ das mulheres empregadas frente a $75 \%$ dos homens. ${ }^{2}$

Estes dados demonstram que a divisão sexual do trabalho demarca espaços e tipos de atividades de forma assimétrica para homens e mulheres, ou seja, as desigualdades no mundo do trabalho se apresentam nos polos das funções - o que é exercido pelo homem e o que é elaborado pela mulher -, das desigualdades salariais, desigualdade diante do desemprego e do tempo parcial. Tais desigualdades são reforçadas pela representação do trabalho masculino como de valor superior ao feminino, onde as condições de emprego não são as mesmas entre homens e mulheres, nem no acesso, nem na permanência (HIRATA, 2001, KERGOAT, 2003).

Neste cenário global de aumento das desigualdades, do empobrecimento e da recomposição das classes sociais (SANTOS, 2014), a migração de pessoas torna-se um desafio para o capitalismo atual. Dados publicados pela $\mathrm{ONU}^{3}$ demonstram que o número de migrantes internacionais representa a marca de 244 milhões no ano de 2015, representando um aumento de $41 \%$ em comparação ao ano 2000, o que corresponde a 3,3\% da população mundial. Destes, 20 milhões são refugiados. Todavia, há uma assimetria quanto aos locais de migração: na Europa, América do Norte e Oceania, os números de migrantes totalizam $10 \%$ da população enquanto na África, América Latina, Ásia e Caribe este percentual é de $2 \%$. Apesar do percentual de deslocamento apresenta-se mais baixo, consideramos que os países do sul global têm sido inseridos nas rotas migratórias não apenas como produtores de emigrantes, mas como lócus de entrada, circulação e permanência de pessoas ocasionado possivelmente pelo cenário global de aumento das desigualdades e da pobreza (SANTOS, 2014; VILLEN, 2015, BAENINGER, 2012).

\footnotetext{
2 Disponível em: https://www.ilo.org/global/research/global-reports/weso/2019/lang-en/index.htm, Acessado em 15 de maio de 2020

${ }_{3}^{3}$ Disponível em: https://nacoesunidas.org/numero-de-migrantes-internacionais-chega-a-cercade-244-milhoes-revela-onu/. Acessado em 08 de janeiro de 2020
} 
É importante destacar que o deslocamento é constitutivo da humanidade, visto que desde sempre homens e mulheres migraram, mas não se trata somente de um ato de deslocamento humano sobre os espaços. É preciso entender que a intensificação da mobilidade humana das últimas décadas, na qual a migração é uma das suas expressões, é determinada pelo conjunto estrutural de efeitos do capitalismo no mundo, que ocasiona o aumento da pobreza e da violência em larga escala, bem como pelas medidas restritivas legais elaboradas pelos Estados nacionais como fechamento de fronteiras. Todavia, não devemos apreender este fenômeno calcado na realidade concreta desmembrado dos elementos de classe, raça, gênero, orientação sexual e nacionalidade, pois, estes fatores impactam de forma diferenciada nos sujeitos e nos países.

Cabe destacar que a compreensão dos deslocamentos deve ser realizada pela mediação dos aparatos estruturais que permeiam a sociabilidade capitalista, bem como os fatores subjetivos que fazem indivíduos, grupos e famílias pensarem nos fluxos migratórios como uma alternativa. Contudo, observa-se que os debates acerca da migração têm invisibilizado a mulher como parte primordial desse processo, principalmente no que concerne à exploração do trabalho, ou então quando as trazem nos estudos apenas em dados estatísticos, deslocadas de uma leitura da realidade, aparecendo como acompanhantes da figura masculina ou para a reunificação familiar.

Neste sentido, diante do cenário contemporâneo de precarização das relações de trabalho, de neoliberalismo, de perdas substanciais dos direitos sociais e de engessamento das lutas sociais, a face perversa do modelo de mundialização do capital tem impelido pessoas a se deslocarem pelos territórios para vender sua mão de obra mais barata alimentando o ciclo de acumulação capitalista, dentre as quais está o trabalho de migrantes, mais especificamente de mulheres racializadas do Sul global, tendo como sustentáculo a divisão sexual e racial do trabalho. (VILLEN, 2015; SASSEN 2003)

Apesar de estarem cada vez mais presentes nos fluxos migratórios, as assimetrias entre homens e mulheres impactam de modos diferenciados os 
âmbitos econômicos, sociais, culturais e políticos. As mulheres migrantes tem ocupado nos fluxos migratórios nichos de trabalho historicamente femininos, seja na mão de obra qualificada ou não e, em sua maioria, permeados por aspectos machistas, racistas e patriarcais, justificados pela divisão sexual do trabalho que tem como princípio a separação entre tarefas e funções consideradas próprias de um ou outro sexo, cuja hierarquia, tarefas e funções de maior valor e reconhecimento social são designadas aos homens, cabendo às mulheres as tarefas mais desvalorizadas, com altas jornadas de trabalho e, portanto, invisíveis. (KERGOAT, 2003)

A feminização dos fluxos migratórios: debates sobre divisão sexual do trabalho e pobreza

As discussões sobre a migração feminina nos espaços acadêmicos e nas políticas começam a aparecem com maior intensidade no contexto de 1980. Até então, no que concerne a população migrante, estes focavam na mobilidade do homem e no "modelo ideal" de migrante, preferencialmente branco, solteiro e heterossexual na busca de emprego. Às mulheres cabiam sua importância na travessia e nos lugares de chegada, não sendo incorporadas como partícipes ativas do processo. Seu papel estava vinculado a reunificação familiar e para cuidar do lar e dos filhos, "pois encarar as mulheres como agentes secundários de processos migratórios, invisíveis em suas especificidades, implicava em ignorar complexidades e heterogeneidades (BAENINGER \& PERES, 2017: 05) do fenômeno migratório.

Até meados de 1980, as discussões pautavam-se em uma visão androcêntrica em que a abordagem dos papéis sociais era feita pelo binarismo masculino e feminino e os papéis desempenhados nos deslocamentos e locais de chegada eram atribuídos aos gêneros e distinguiam-se de acordo com as atividades de produção e reprodução. As assimetrias estavam relacionadas ao modelo do "ser migrante", situado no provedor e trabalhador, representado, portanto, pela figura masculina. (MOROKVASIC, 2002) 
Foi a partir da a inserção dos debates de gênero na academia e das lutas feministas que pautavam temáticas sobre a reprodução social, necessidade da visibilidade das mulheres nos espaços públicos, em 1980, que a temática de mobilidade humana passa a incorporar as mulheres não mais como acompanhantes, mas como sujeitos participantes dos fluxos (BAENINGER e PERES, 2017). Nesse período há uma intensificação quantitativa de mulheres que passam a se deslocar em busca de melhores condições de vida diante das respostas a crise capitalista que aumentou as desigualdades e o empobrecimento da classe trabalhadora, sobremaneira das mulheres. (MARINUCCI, 2012; MOROKVASIC, 2002)

Cabe destacar que o papel femininos nos fluxos migratórios foi abordado inicialmente com a diferenciação entre os sexos, todavia não abarcava uma análise mais rigorosa sobre as diversas variáveis, tais como taxas e inserção em empregos, formação de redes sociais, aspectos familiares, foi com o aprofundamento dos debates que a visibilidade destas permitiram ampliar as discussões para elementos como o papel nos países de chegada, transição e permanecia, o cotidiano, as redes migratórias e a divisão sexual e racial do trabalho (MARINUCCI, 2012). De fato, estes apresentaram uma mudança na compreensão das condições de vida e trabalho destas mulheres nos fluxos migratórios, "indo além das descrições de diferenças entre homens e mulheres, as teorias de migração avançaram no sentido de compreender as experiências das mulheres em esferas específicas - família, domicílio, mercado de trabalho (BAENINGER \& PERES, 2017: 02).

No que concerne a maior participação qualitativa e quantitativa das mulheres, fenômeno denominado de feminização da migração, podemos destacar fatores que impelem a saída de seus países de origem como a fuga de guerras, de casamentos, desastres naturais, perseguições por etnias, religiões, questões políticas ou pela busca de trabalho, mas também que essa presença qualitativa se dá na relação autônoma da mulher que escolhe migrar em busca de melhores condições de trabalho e de estudos (MARINUCCI, 2012; MOROKVASIC, 2002). Embora, existam fatores individuais que impulsionem 
a saída de mulheres de seus países, estes estão situados em um cenário que tem sido funcional ao sistema capitalista, visto que há uma exploração e expropriação das mulheres, principalmente as racializadas.

Há mais de 40 anos, as mulheres representavam cerca da metade dos migrantes no mundo. No que se refere à migração latino-americana e caribenha, as mulheres migrantes que viviam nos Estados Unidos somavam, em termos absolutos, dois milhões em 1980. Em 2010, já totalizavam dez milhões. Na Espanha, o número de migrantes mulheres somava, em 2001, 464 mil, passando a 1,4 milhões em 2011 (ROSAS, 2013: 131).

Este aumento numérico de mulheres nos fluxos migratórios também tem sido facilitado pelas redes migratórias que oferecem apoio e informações que auxiliam na entrada e permanência destas nos países. Destacamos que apesar do aumento do número de mulheres no contexto migratório, estas permanecem invisibilizadas no mercado de trabalho, pois de um lado a presença masculina demarca historicamente uma imagem de migrante trabalhador e, de outro, porque os espaços em que estas ocupam são de atividades "tipicamente femininas", como setores de serviços, empregadas domésticas, denotando uma precariedade e informalidade do trabalho e do capitalismo tem se apropriado dessas diferenças para explorar e expropriar as mulheres migrantes e se estiverem em situações de irregularidade, este contexto se agrava.

Apesar do número de mulheres que migram para trabalhos considerados qualificados, a migração feminina é vista como um dos elementos que fortalecem a precariedade do trabalho destas, pois estão concentradas, majoritariamente, em trabalhos domésticos e de cuidados, informais, prostituição e de tráfico de mulheres. (SASSEN, 2003)

A precariedade do trabalho das mulheres tem como base a divisão sexual do trabalho que atribui significados e hierarquias que produzem desigualdades entre os gêneros a partir da determinação do valor superior atribuído ao que é realizado pelos homens e negatividade às atividades desempenhadas pelas mulheres. É valido ressaltar que o sistema capitalista se apropria da subordinação das mulheres para obter mais lucro, pois sendo 
“inferiores aos homens" estão sujeitas a receber salários baixos, se submeter a condições de trabalho precarizadas e sem garantias trabalhistas, além de terem suas atividades desvalorizadas das atividades. (HIRATA, 2004)

Desta feita, compreende-se que a migração de mulheres implica em determinações para a produção e reprodução do capital a partir de uma superexploração da sua força de trabalho tanto no âmbito público como no privado. Neste, pela utilização e responsabilização das mulheres na reprodução social e, na esfera pública, pela desvalorização e exploração no mundo produtivo, ou seja, no mercado de trabalho.

Com o aumento e participação das mulheres na esfera produtiva a partir de 1980, principalmente nos países da Europa, e a não responsabilização masculina pelas atividades reprodutivas, coube a outras mulheres realizá-las. Diante disto, são as mulheres migrantes racializadas que são impelidas a estarem no trabalho doméstico e no setor de cuidado. Cabem a estas o deslocamento para a esfera do cuidado enquanto seus filhos e familiares ficam sobre os cuidados de outrem, preferencialmente de outras mulheres; gerando uma rede de cuidados.

As atividades vinculadas ao trabalho doméstico e de cuidados demandam mais tempo do que a de trabalhadoras locais, com um salário baixo, longas jornadas de trabalho e quando são migrantes indocumentadas ganhavam menos ainda. Atreladas a estes fatores que reforçam a divisão sexual e racial do trabalho, as condições de vida destas nos países de origem as mobilizam ao deslocamento, embora muitas trabalhadoras tenham a sua condição de vida agravada nos países de chegada. (JOSEPH \& HANDERSON, 2015; VILLEN, 2015). Muitas mulheres são submetidas a longas jornadas de trabalho, algumas trabalhadoras moram no mesmo espaço do trabalho, com longas jornadas em troca de alimentação e moradia, sofrendo abusos e violência. (DUTRA, 2013)

Quanto a participação de migrantes no mercado de trabalho, os estudos têm demonstrado que as mulheres migrantes estão situadas nos polos do mercado de trabalho: qualificado e não qualificado (VILLEN, 2013; SASSEN, 2006). Este, ocupado majoritariamente por mulheres racializadas 
advindas, prioritariamente, de países do Sul global que se deslocam para países da Europa e Estados Unidos para executar trabalhos vinculados a esfera doméstica e de cuidados. O que se denomina de trabalho não qualificado caracteriza-se por atividades realizadas em setores precarizados, informais e mal remunerados e acontece no caso das mulheres migrantes em uma relação entre irregularidade e precarização, pois são trabalhos precários e que concentram, particularmente, em mulheres não-brancas.

Quanto as trabalhadoras qualificadas, como destaca o estudo de Villen (2015), referem-se a mulheres que se deslocam para os países do norte global e que representam um baixo índice em termos quantitativos, principalmente no que concerne a ocupação em cargos mais valorizados e de direção. A autora afirma que, mesmo com diplomas e especializações, as migrantes são mal remuneradas quando comparadas com trabalhadoras nacionais. E que ao estarem em mobilidade territorial perdem os cargos, promoções e funções anteriores, além de haver um índice de desistência diante da dificuldade de conciliar o emprego, a migração e a vida familiar. Todavia, "a imposição da mobilidade, em muitos casos, impede a continuidade ou promoção em razão do desafio de conciliar a mobilidade com a vida familiar" (VILLEN, 2015: 10). A ocupação em cargos qualificados dá-se, muitas vezes, sobre a imposição pelas empresas no discurso para a estabilização da carreira. Todavia, essas migrantes em trabalhos que são bem remunerados, qualificados e de elevados postos, ainda representam a minoria de migrantes mulheres.

Destacamos que as migrantes cumprem, também, um papel importante econômico não apenas nos lugares para os quais migram, mas para os lugares dos quais saíram, pois enviam remessas de dinheiro para sua família. As mulheres, devido aos novos arranjos familiares, ficam entre provedoras e chefes de família, aumentando o empobrecimento familiar (DUTRA, 2013).

A relação entre feminização da migração, do trabalho e da pobreza, nos permite considerar que o aumento do trabalho feminino no mundo não foi concomitante à melhoria da condição de vida tampouco da sua condição de gênero (NOGUEIRA, 2004; YANNOULAS, 2011). No que concerne às 
mulheres e pobreza, conclui-se que as mulheres de baixa renda são as mais atingidas pelo modelo econômico e cultural vigente, pois são exploradas, oprimidas e discriminadas tanto pelo sexo como pela classe, estando no limite da sobrevivência com relação as suas necessidades básicas (VILLEN, 2015; DUTRA, 2103b; SASSEN, 2003).

Segundo dados da ONU, 70\% dos pobres do mundo são mulheres, que, por sua vez, têm despontado no cenário das migrações internas e externas, enquanto sujeitos autônomos, na perspectiva de melhores condições de vida para si, e nos casos daquelas que são mães, para seus filhas e filhos. Assim, a tentativa de "conciliação" entre o trabalho produtivo e reprodutivo se dá devido à necessidade de complementar a renda familiar.

Desemprego feminino, mas também desemprego masculino em setores tradicionais, multiplicou a pressão exercida sobre as mulheres para encontrar formas de garantir a sobrevivência doméstica. A produção de alimentos de subsistência, trabalho informal, emigração, prostituição. Todas essas atividades adquiriu uma importância muito maior como opções de sobrevivência para mulheres (SASSEN, 2003: 51).

O que a realidade apresenta demonstra que a inserção das mulheres em profissões precárias, trabalhos temporários e informais junto à desvalorização social vem imbuída de níveis inferiores de salário e na dificuldade da sua integração e participação em associações e sindicatos:

Assiste-se a uma dupla transformação paradoxal do trabalho, porque ela parece ir em sentido oposto; de um lado, a implicação do sujeito no processo de trabalho e, de outro, a precarização do emprego, com o desenvolvimento de formas flexíveis de trabalho e o crescimento do desemprego. Este último movimento é grande e globalizado, e parece dizer respeito às mulheres, em primeiro lugar, enquanto a implicação requerida pelos novos modelos de organização do trabalho parece dizer respeito tendencialmente aos assalariados do sexo masculino das grandes empresas industriais dos países do Norte (HIRATA \& LE DOARÉ, 1999: 10). 
Portanto, a migração feminina está relacionada ao conjunto de desigualdades, que põe às mulheres a encontrar na alternativa de migrar a busca para melhorar a condição de vida de si mesma e dos familiares. Pensar em migração feminina é pensar em seus diversos aspectos, tais como: as consequências dos movimentos migratórios sobre a autonomia feminina; as práticas familiares transnacionais e a maternidade a distância; as cadeias globais de cuidado e o trabalho doméstico e as instituições e políticas migratórias como reprodutoras de desigualdades.

A pesquisa realizada por Joseph \& Handerson (2015) sobre migrantes haitianas na França e no Brasil retrata que as mulheres entrevistadas ao chegarem nestes países não tiveram sua documentação e qualificação profissional reconhecida imediatamente, tendo que trabalhar nestes países como empregadas domésticas. A difícil situação de vida dessas mulheres intensificase, pois muitas enviam remessas para as famílias que ficam no país de origem e, com baixas remunerações, acabam endividadas. Além disso passam por situações de preconceito racial e xenofobia. No caso dos denominados países em desenvolvimento, as mulheres estão sendo, cada vez mais, responsáveis pela sobrevivência, não só de suas famílias, mas também da economia de seus países de origem, através das remessas enviadas (SASSEN, 2003: 50):

Neste sentido, "mulheres e imigrantes" emergem como o
equivalente do proletariado, um proletariado que se
desenvolve fora dos países de origem. Além disso e, por
outro lado, as exigências da força do mais alto nível
profissional e gerencial nas cidades globais são tais que os
modos atuais de lidar com tarefas domésticas e estilos de
vida se tornam insuficiente. Como consequência, estamos
observando o retorno das chamadas "classes de servidão",
compostas principalmente por migrantes e mulheres
migrantes.

Contudo, não podemos pensar as mulheres migrantes como uma construção uniformizada, mas compreender que são atravessadas pelas relações de gênero e raça, bem como também exige a reorganização na esfera da 
reprodução, visto que muitas deixam seus filhos para cuidar dos filhos de outras mulheres. Pedone (2017: 130) retrata que:

apesar de aceitar-se, no plano econômico que a transferência transnacional do trabalho reprodutivo é uma consequência a nova estratificação do mercado de trabalho em nível mundial e gera uma demanda por mão de obra feminina que tem incrementado os movimentos Norte-Sul (acrescentamos Sul-Sul), o paradoxo nos lembra que as mulheres migrantes deixam seu papel de cuidadora no local de origem para migrar e cuidar de crianças, idosos e casas em troca de um salário.

As famílias necessitam dos recursos das mulheres e das atividades que geram remessas pelas mulheres migrantes, haja vista que o trabalho realizado por estas tem implicações econômicas, sociais e políticas nos países de chegada como nos de origem, por meio do valor que geram. O envio de remessas, portanto, demonstra que as migrantes ficam mais vulneráveis, pois ao enviar dinheiro para seus países de origem, no intuito de assegurar a sobrevivência dos familiares, filhos e do pagamento de outras mulheres que realizam as atividades da reprodução da vida, ficam com o dinheiro para itens básicos como transporte e alimentação, estando assim, submetidas a abusos e exploração (DUTRA, 2017).

Observa-se que as mulheres que migram na busca de melhores condições de vida cumprem um papel importante na estrutura familiar, o que pode modificar as relações de poder, visto que o rendimento familiar vem deste trabalho (BAENINGER \& PERES, 2012). Todavia o papel como reprodutora na esfera do lar seja no país de origem como na mobilidade não modifica a condição de naturalização de suas atividades, ou seja, apesar de enviar as remessas sua condição de exploração não diminui, tampouco as responsabilidades e atividades desempenhadas na esfera familiar.

Somada essas questões de exploração do trabalho à divisão sexual e racial observamos que há uma sobrecarga das mulheres, em específico as racializadas. No exemplo das haitianas, Joseph \& Handerson (2015) abordam que o racismo e a xenofobia fazem com que mulheres mudem frequentemente 
de empregos. Assim, a questão racial é um elemento importante para entender como esses aspectos reverberam no aumento da exploração do trabalho, visto que há uma valorização fenotípica em alguns lócus laborais em detrimento de outros e nas desigualdades salariais.

A condição de exploração do trabalho feminino tende a se intensificar com a irregularidade de algumas migrantes, que tem os salários mais baixos, jornadas de trabalho mais extensas, ou ao desemprego e muitas são submetidas a prostituição e tráfico de mulheres. E, por estarem sem documentos, tem maiores dificuldades de acessar políticas públicas e os setores de serviços. (DUTRA,2013). A ilegalidade/irregularidade apresenta-se como estratégias para criar uma indústria lucrativa da migração irregular (coiotes, contrabandistas, traficantes, empresários, redes de tráfico, empresas multinacionais) ao tempo em que se constitui como aparato jurídico e político de limites dos Estados-nação reforçados em portos, aeroportos, estradas etc. Os limites impostos pelas fronteiras apresentam também o limiar no que concerne a gênero, raça, etnia, classe e geração (JOSEPH \& HANDERSON 2015; SASSEN, 2003). As migrantes em situação irregular vivem em uma condição de violação de direitos.

Diante do exposto, consideramos que as mulheres que migram, principalmente aquelas que encontram a mobilidade como alternativa para a melhoria das condições de vida, de pobreza e trabalho, estão submetidas as mais diversas situações de vulnerabilidade, começando pelo deslocamento territorial. Dentre outros elementos, estão a ausência de direitos, de políticas migratórias que especifiquem a condição da trabalhadora, a ausência de documentos ligados as burocracias estatais, o entendimento da língua originária que impossibilitam a informação, gerando barreiras linguísticas e xenofobia, o que impedem a comunicação e causam isolamento das imigrantes.

\section{Considerações sobre a migração de mulheres}

A discussão acerca da migração e o papel feminino nos fluxos de deslocamento demonstra que mulheres e homens têm experiências migratórias 
diferentes. Assentadas na divisão sexual e racial do trabalho como sustentáculo para acentuar a exploração e a opressão sobre as mulheres, a feminização da migração mostra a face acentuada da condição destas com o processo de exploração da mão de obra mais barata, em que, ao se deslocarem na busca de melhores condições de vida, frente a perversidade do sistema capitalista, ficam subsumidas a trabalhos em níveis precários, informais e com rendas inferiores aos homens.

As mulheres migrantes estão subjugadas ao mercado de trabalho temporário, flexível e sem estabilidade ou proteção social, visto que a força de trabalho de migrantes, principalmente indocumentada, adapta-se à lógica de acumulação ampliada do capital. Estes aspectos têm implicações reais e dramáticas na vida dos sujeitos, pois explora a força de trabalho, aprofundando as expropriações a toda velocidade, intensificando as desigualdades e comprometendo a vida social dos trabalhadores, além de reduzir as formas de resistências. Neste sentido, o que temos é que os deslocamentos e migrações humanas tornaram-se um desafio político contemporâneo.

No que concerne à migração por atividades laborais, observa-se uma relação estreita entre fluxos de pessoas e trabalho e que as rotas estão de acordo com a dinâmica do capital, que constrói e destrói postos de trabalho. Quanto à especificidade de sexo, observa-se que muitas mulheres migram com perspectivas da proposta laboral e, principalmente, o sustento familiar, mas que ainda permanecem "invisíveis" na migração. De um lado, porque a presença masculina já confere a imagem de homens trabalhadores e, de outro, porque os empregos que as mulheres conseguem se inserir são, em sua maioria, nos setores de serviços ou mesmo estão sem ocupação, denotando a precariedade do trabalho.

Neste sentido, a divisão sexual e racial do trabalho se apresenta de forma hierarquizada, assimétrica e desigual expressas nos espaços de produção e reprodução social que encontra sua determinação na relação exploração, constitutiva da relação capital e trabalho, e dominação. Cabe ressaltar que essa divisão e o racismo cumprem uma função primordial no capital que é o de 
acumulação capitalista através de uma maior exploração da força do trabalho de mulheres, sobremaneira as racializadas, seja com a participação destas nas esferas produtivas de baixa remuneração bem como no trabalho doméstico remunerado e/ou mal pago (KERGOAT, 2003).

Cabe ressaltar que, nos últimos anos, outros debates referentes a migração feminina têm apresentado particularidades sobre os papéis executados por estas, como o a práticas familiares, cadeias globais de cuidado e trabalho doméstico. Destacamos que houve um aumento de mulheres solteiras ou que migram sozinhas, sem companheiros ou filhos, o que pode ser analisado diante da reconfiguração no mercado de trabalho, visto que os trabalhos se limitam para alguns membros familiares e isto tem impactos sobre o entendimento dos deslocamentos femininos.

Diante do exposto, consideramos salutar que para a compreensão da relação entre mulheres migrantes racializadas e mercado de trabalho, a discussão da divisão sexual e racial do trabalho é, pois, fundante, tendo como expressões a expropriação, a exploração e a dominação.

Referências

BAENINGER, Rosana. et al. Imigração Haitiana no Brasil. Jundiaí: Paco Editorial, 2017.

. Migração Feminina: um debate teórico e metodológico no âmbito dos estudos de gênero. XVIII Encontro Nacional de Estudos Populacionais. São Paulo, 2012.

- Migrações Sul-Sul. In BAENINGER, Rosana; BÓGUS, Lúcia Machado; MOREIRA, Júlia Bertino et alii (orgs.). Migrações Sul-Sul. $2^{\text {a }}$ edição. Campinas SP: Núcleo de Estudos de População "Elza Berquó" Nepo/Unicamp, 2018.

; PERES, R. Migração de crise: a migração haitiana para o Brasil. Revista Brasileira de Estudos de População, São Paulo, SP, v. 34, n. 1, p. 119$144,2017$.

CEPAL. Panorama Social da América Latina 2004. Disponível em: http://www.eclac.cl/cgi-in/getProd.asp?xml=/publicaciones/xml. Acesso em: 23 mar. 2019. 
DUTRA, Delia da S. M. Mulheres migrantes peruanas em Brasília. O trabalho doméstico e a produção do espaço na cidade. Brasília: CSEM; Sorocaba, SP: OJM, 2013.

Mulheres, migrantes, trabalhadoras: a segregação no mercado de trabalho. Revista Interdisciplinar da Mobilidade Humana, Brasília, DF, v. 21, n. $40, \quad$ p. 177-193, jun. 2013b. Disponível em:<http://www.scielo.br/pdf/remhu/v21n40/11.pdf $>$. Acesso em: 10 mar. 2019 .

. et. al. Os estrangeiros no mercado de trabalho formal brasileiro: perfil geral na série 2011, 2012 e 2013. In. CAVALCANTI, Leonardo; OLIVEIRA, Antonio Tadeu; TONHATI, Tânia (Orgs.). A inserção dos imigrantes no mercado de trabalho brasileiro. Brasília: Cadernos do Observatório das Migrações Internacionais, 2015, p.74-135.

HANDERSON, J.; JOSEPH, R.-M. As relações de gênero, de classe e de raça: mulheres migrantes haitianas na França e no Brasil. Revista de Estudos e Pesquisas sobre as Américas, Brasília, DF, v. 9, n. 2, p. 1-33, 2015. Disponível em: <http://periodicos.unb.br/ index.php/repam/article/view/17266>. Acesso em: 12 jun. 2020.

HIRATA, Helena. Globalização e Divisão Sexual do Trabalho. Cadernos Pagu, pp. 139-136, 2001.

. Nova divisão sexual do trabalho? São Paulo: Boitempo, 2004.

HIRATA, Helena.; LÊ DOARÉ, H. Os paradoxos da globalização. Cadernos Sempreviva. Sempreviva Organização Feminista (SOF). São Paulo, 1999.

INSTITUTO BRASILEIRO DE GEOGRAFIA E ESTATÍSTICA.

Censo Demográfico 2010. Resultados Gerais da Amostra. Rio de Janeiro: IBGE, 2010.

KERGOAT, Danièle. Divisão sexual do trabalho e relações sociais de sexo. In: EMÍLIO, M.; GODINHO, T.; NOBRE, M.; TEIXEIRA, M. (Orgs.). Trabalho e cidadania ativa para as mulheres: desafios para as Políticas Públicas. SP: Coordenadoria Especial da Mulher, 2003. 152p. (Coleção Caderno da Coordenadoria Especial da Mulher, 3).

Divisão sexual do trabalho e relações sociais de sexo. In: HIRATA, Helena [et al.] (orgs.). Dicionário crítico do feminismo. São Paulo: Editora UNESP, 2009.

Dinâmica e consubstancialidade das relações sociais. In: Novos Estudos CEBRAP, n. 86, março 2010. 
MARINUCCI, Roberto. Feminização das Migrações? Disponível em: http://www.csem.org.br/pdfs/feminizacao_das_migracoes_

roberto_marinucci2007.pdf, Acesso em setembro, 2012. [Cf. versão em inglês do artigo publicada na REMHU, v.15, n.29, 2007].

MAROKVASIC, M. L'a mobilité transnacionale comme resource: le cas de migrants de l'Europe de l'Est. Culture et Conclts, 32, 2002.

NOGUEIRA, Cláudia Mazzei. O trabalho duplicado: a divisão sexual no trabalho e na reprodução - Um estudo das trabalhadoras do telemarketing. São Paulo: Expressão Popular, 2004.

ORGANIZAÇÃO Internacional do Trabalho - OIT. Cidadania, direitos humanos e tráfico de pessoas: manual para as promotoras legais populares. Brasília, 2009.

. Uma Aliança Global contra o Trabalho Forçado. Brasília, 2005.

ORGANIZAÇÃO das Nações Unidas - ONU. A armadilha do gênero; mulher violência e pobreza. Relatório da ONU. Anistia Internacional, 2009.

. Relatório da Divisão de População do Departamento de Assuntos Econômicos e Sociais, 2005.

PEDONE, Cláudia. Cadenas y redes migratorias: propuesta metodológica para el análisis diacrónico-temporal de los procesos migratórios. UNED - Empiria: Revista de Metodología de Ciencias Sociales. n. 19, p. 101-132, 2017.

SANTOS, Cleusa. Migração e trabalho. Desvendando o enigma da superpopulação. In: Anais XIV Encontro Nacional de Pesquisadores em Serviço Social realizado de 30 de novembro a 04 de dezembro de 2014, em Natal/RN.

SASSEN, Saskia. Contrageografía de la globalización. Madrid: Traficantes de Sueños. 2003.

de survie et leursacteurs. Cahiers du Genre, n. 40, 2006, p. 67-89.

Expulsões: brutalidade e complexidade na economia global. 1.ed. Rio de Janeiro/São Paulo: Paz e Terra. 2016

VILLEN, Patricia. Imigração na modernização dependente: "braços civilizatórios" e a atual configuração polarizada, Tese de Doutorado, Universidade Estadual de Campinas, 2015.

. Mulheres na imigração qualificada e de baixa qualificação: uma modalidade da divisão sexual do trabalho no Brasil. In: CONGRESSO 
LATINO-AMERICANO DE ESTUDOS DO TRABALHO, 7., 2013, São Paulo. Anais... São Paulo: ALAST, 2013.Disponível em: $<$ http://docplayer.com.br/16411893-Mulheres-na-imigracao-qualificada-e-debaixa-qualificacao-uma-modalidade-dadivisao-sexual-do-trabalho-nobrasil.html\#show_full_text>. Acesso em: 29 jun. 2019.

YANNOULAS, Silvia. Feminização ou feminilização? Apontamentos em torno de uma categoria. Temporalis, Brasilia, ano 11, n.22, p.271-292, jul./dez. 2011.

Recebido em: 7 de junho de 2020 Aceito em: 9 de setembro de 2020 